Hanson, V. et al. (2017). Knowledge and practice of breast self-examination among rural women in South-West Nigeria: Implications for development of women empowerment

programme.

African Journal of Nursing and Midwifery, 19(1): $144-156$.

http://dx.doi.org/10.25159/2520-5293/950

UNIVERSITY of the

WESTERN CAPE

\title{
Knowledge and practice of breast self-examination among rural women in South- West Nigeria: Implications for development of women empowerment programme
}

Victoria Hanson, Olyinka Adejumo and Brian van Wyk

\begin{abstract}
Cancer is a major public health concern globally. In Nigeria, over 10000 cancer deaths and 250000 new cases of cancer are recorded yearly. It was reported that the number of women at risk of breast cancer increased progressively from 24.5 million in 1990 to about 40 million in 2010. Due to the progressive nature of breast cancer, early detection can improve survival chances of women and reduce death. Breast self-examination (BSE) is a relatively simple and low-cost intervention for women to detect breast cancer before the disease has progressed too far. This paper reports on knowledge and practices of BSE among rural women, living in Iddo Local Government Area (LGA) in south-west Nigeria. A cross-sectional survey was conducted among 345 women, aged 20-60 years, from five selected villages in Iddo LGA, who volunteered to participate in an empowerment programme to promote breast cancer prevention. Data were collected using an intervieweradministered questionnaire and analysed using descriptive and basic inferential statistics. The majority of participating women had low levels of knowledge about BSE (75.1\%) and did not practise BSE (76.5\%). It was also found that marital status, occupation and income levels were significantly associated with knowledge and practice of BSE. The main reasons offered for not practising BSE were lack of knowledge on the timing of when to do it (85.5\%) and not knowing how to do it (87.8\%). There is a need to design an intervention programme to educate women on the importance of early diagnosis of breast cancer and to empower them with knowledge on how to practice BSE.
\end{abstract}

\section{Introduction and background information}

Breast cancer is a feared disease, not only because it is life threatening, but also because it can affect a woman's sense of self, her sexuality and her femininity. Moreover, breast cancer is a topic that is not freely discussed because of certain taboos associated with it, and its documentation among the rural population is usually neglected. The incidence of breast cancer has grown by more than $20 \%$ globally, and related mortality has increased by 14\% (American Cancer Society 2011). Cancer accounts for $13 \%$ of all deaths globally, of which $70 \%$ occurred in the middle and the low income countries (World Health Organization (WHO) 2008). In Nigeria, over 10000 cancer deaths and 250 000 new cases of cancer are recorded yearly (Akinde, Phillips, Oguntunde and Afolayan 2015). Most Nigerian women $(70 \%)$ report during the late stages of breast cancer when little or no benefit can be derived from any form of therapy (Okobia, Bunker, Okonofua and Osime 2006). 
The current methods to screen for breast cancer include breast self-examination (BSE), clinical breast examination and mammography. An ideal breast cancer screening test that would be most fitting in developing country contexts for early detection of breast cancer is breast self-examination because it is simple, inexpensive and effective (Forbes, Linsell, Atkins, Burgess, Tucker, Omar and Ramirez 2011). Despite its simplicity and cost-effectiveness, many women do not practise BSE (Ahuja and Chakrabarti 2010). Studies have shown that many women, particularly the poor, the medically underserved and of ethnic minority, do not practise BSE (Mugivhi, Maree and Wright 2011).

This article describes BSE knowledge and practices among the rural women living in the Iddo Local Government Area (LGA) of Oyo State, Nigeria.

\section{Statement of the research problem}

The menace that occurs with the women diagnosed with breast cancer re- mains enormous, and it is similar to the women with HIV in terms of care. Little attention is given to creating awareness on breast cancer among women in the rural areas of the developing countries. Early detection remains the most effective method to combat breast cancer. Women in the rural areas are often not aware of the preventive measures of breast cancer, particularly BSE, and this remains a significant barrier to $\mathrm{BSE}$ as a practice. In addition to health information, other barriers to the practice of health behaviours such as BSE need to be identified.

\section{Research questions}

1. What is the knowledge of BSE among childbearing women in a rural setting of the Iddo community of Nigeria?

2. What are the uptakes of BSE practice among childbearing women in the Iddo community?

3. Do socio-demographic variables of women have any effect on the knowledge and practice of BSE?

\section{Research methodology}

Adescriptive and analytical cross-sectional survey was conducted among 345 women, aged 20-60 years, from five selected villages of the Iddo LGA of Oyo State, Nigeria. The participants were recruited through purposive sampling from the market place, antenatal clinic, infant welfare clinic, churches, mosques, and their houses. The purpose of the study, which was to develop an empowerment programme for women in the Iddo LGA for BSE practice towards the prevention of breast cancer, was explained to the participants. The participants were informed that the study would involve their active and full participation. Data on knowledge about BSE and BSE practice were collected through self- and interview-administered questionnaires.

Descriptive and basic inferential statistics were calculated using Statistical Package for Social Sciences (version 21). Cross-tabulation was used to examine the significance of relationships between socio-demographic variables and knowledge about and practice of BSE. Associations were tested using the chi-square test, and p-values $<0.05$ were used as cut-off for significance. 
The survey instrument was pretested to assess validity and reliability. Content validity refers to the extent to which the items of the questionnaire assess the content and the components of the variable to measure (Brink et al. 2011). Content validity is further based on the extent to which the measurement reflects the specific intended domain of the content. This approach ensures that a good, detailed description of the content domain measured was represented in the items of the questionnaire. A pilot study using 50 women in a village in the study setting was conducted to test the instrument for further adjustment to avoid ambiguity. The questionnaire was translated into the local language of the study setting. The final copy of the questionnaire was developed based on the outcome of the pilot study and the input from the experts.

Instrument bias was reduced by using a structured questionnaire that was adapted from the Health Belief Model (Champion and Strecher 2002). The reliability of the instrument was tested using Cronbach's alpha coefficient; the split-half reliability method was used to test the instrument. There was positive correlation between knowledge and practice of BSE and the socio-demographic variables, thereby adding knowledge and promoting the need for empowerment development. The Cronbach's alpha coefficient value was 0.7 .

Ethics clearance was obtained from the University of Western Cape Senate research committee and the National Ministry of Health. Full disclosure of the study objective was made available to the participants. A consent form was signed and thumb-printing was obtained. Participation in the study was voluntary and based on informed consent; they were informed that they can withdraw at any time. They were assured of the anonymity and confidentiality of their responses throughout the study.

\section{Research results}

The majority of the participants $(70.1 \%)$ were drawn from the Iddo and Apete villages, the rest were drawn from Ogundele/Shiba (16.2\%), Gbekuba (7.5\%) and Ilaju (6.1\%). More than two-thirds (70.1\%) of participating women were between 20 and 40 years, the rest $(29.9 \%)$ were 41 years and above. Most participants were married (87.5\%). A little above half (51.1\%) of the participants were not educated, $33.3 \%$ had primary education and only $11.6 \%$ had secondary education. The majority of the participants $(93.8 \%)$ engaged in trading, farming or were full-time housewives, while less than $10 \%$ were civil servants. Religious affiliation was predominantly Christian (59.7\%). The majority of the participants $(71.3 \%)$ were reported to have low and insufficient income levels. 


\section{Knowledge of breast self-examination}

Table 1: Knowledge of breast self-examination $(\mathrm{N}=345)$

\begin{tabular}{|l|l|l|l|}
\hline & Knowledge items & $\begin{array}{l}\text { Yes } \\
(\%)\end{array}$ & No (\%) \\
\hline $\begin{array}{l}\text { *. } \\
*\end{array}$ & $\begin{array}{l}\text { A woman is expected to do BSE 2nd or } 3^{\text {rd }} \text { day after menstruation } \\
\text { monthly. }\end{array}$ & 27.2 & 72.8 \\
\hline $\begin{array}{l}2 . \\
*\end{array}$ & $\begin{array}{l}\text { Women with irregular menses or those that have reached } \\
\text { menopause should do breast self-examination on a particular day } \\
\text { monthly. }\end{array}$ & 14.5 & 85.5 \\
\hline $\begin{array}{l}3 . \\
*\end{array}$ & $\begin{array}{l}\text { Three processes of breast self-examination are standing in front } \\
\text { of a mirror, lying down and when bathing. }\end{array}$ & 29.9 & 70.1 \\
\hline $\begin{array}{l}4 . \\
*\end{array}$ & $\begin{array}{l}\text { Breast self-examination is divided into two: } \\
\text { (i) Observation }\end{array}$ & 32.2 & 67.8 \\
\hline $\begin{array}{l}5 . \\
*\end{array}$ & $\begin{array}{l}\text { During breast self-examination, attention should be paid to the } \\
\text { armpit, the neck and the breast for lumps. }\end{array}$ & 24.9 & 75.1 \\
\hline $\begin{array}{l}6 . \\
*\end{array}$ & $\begin{array}{l}\text { The advantage of BSE is that a woman is in the best position to } \\
\text { ascertain if there are changes in her breasts. }\end{array}$ & 29.0 & 71.0 \\
\hline 7. & Thin people have the advantage of detecting breast lumps easily. & 23.8 & 76.2 \\
\hline 8. & It is more difficult for fat women to detect breast lumps. & 21.4 & 78.6 \\
\hline 9. & $\begin{array}{l}\text { Younger women (<50 years) discover breast lumps than the older } \\
\text { women. }\end{array}$ & 23.5 & 76.5 \\
\hline & Total & 25.2 & 74.8 \\
\hline
\end{tabular}

Table 1 shows that the majority of the participants (74.8\%) had inadequate knowledge of when and how BSE should be done. Few participants $(27.2 \%)$ declared that they knew the correct timing for BSE. Most participants $(85.5 \%)$ were not aware of the need for menopausal women to examine their breasts. The majority of the women $(70.1 \%$ ) had no knowledge about the various positions that can be used for BSE. Less than a quarter of participating women (24.9\%) declared that they can identify the areas of the breast to pay attention to when examining the breast. Further more, $71.0 \%$ of the participants did not know about the advantages of BSE where a woman is in the best position to ascertain if there are changes in their breasts. The majority of women (76.2\%) had no knowledge that thin people have the advantage of detecting breast lumps easily. Less than a quarter of women $(21.4 \%)$ did not know that fat women find it difficult to detect breast lumps. The majority of respondents $(76.5 \%)$ declared that they did not know that younger women $(<50$ years $)$ discover breast lumps more than older women. All the knowledge items were significant at $\mathrm{p}<0.05$. 
Table 2: Knowledge of breast self-examination by socio-demographic characteristics $(\mathrm{N}=345)$

\begin{tabular}{|c|c|c|c|c|c|}
\hline \multirow{3}{*}{ Age (in years) } & \multicolumn{4}{|c|}{ Knowledge of breast self-examination } & \multirow{3}{*}{$\begin{array}{l}p \text {-value } \\
0.001244^{*}\end{array}$} \\
\hline & \multicolumn{2}{|c|}{ Yes (\%) } & \multicolumn{2}{|c|}{ No $(\%)$} & \\
\hline & & & & & \\
\hline $20-30$ & 43 & 33.6 & 85 & 66.4 & \\
\hline $31-40$ & 14 & 12.3 & 100 & 87.3 & \\
\hline $41-50$ & 18 & 28.1 & 46 & 71.9 & \\
\hline$>50$ & 12 & 30.8 & 27 & 69.2 & \\
\hline Marital status & & & & & $0.004^{*}$ \\
\hline Never married & 19 & 44.2 & 24 & 55.8 & \\
\hline Ever Married & 68 & 22.5 & 234 & 77.5 & \\
\hline Education & & & & & $0.0264^{*}$ \\
\hline No education & 39 & 20.5 & 151 & 79.5 & \\
\hline Primary & 32 & 27.8 & 83 & 72.2 & \\
\hline Secondary & 16 & 40.0 & 24 & 60.0 & \\
\hline Occupation & & & & & $0.0003^{*}$ \\
\hline $\begin{array}{l}\text { Trading/Housewife/ } \\
\text { Farming }\end{array}$ & 74 & 22.8 & 250 & 77.2 & \\
\hline Civil service & 13 & 61.9 & 8 & 38.1 & \\
\hline Religion & & & & & 0.45 \\
\hline Christianity & 55 & 26.7 & 151 & 73.3 & \\
\hline Islam/Traditional & 32 & 23.0 & 107 & 77.0 & \\
\hline Income level & & & & & $0.008^{*}$ \\
\hline Sufficient & 35 & 35.4 & 64 & 64.6 & \\
\hline Insufficient & 52 & 21.1 & 194 & 78.9 & \\
\hline
\end{tabular}

*Significant at $p>0.05$.

Table 2 shows the associations between socio-demographic characteristics of the respondents and their knowledge of BSE. More married participants reported no knowledge of BSE (compared with those who were never married $(77.5 \%$ vs $55.8 \%$; $=0.004)$ ). Significantly more participants with no education had no knowledge of BSE compared with those who had primary education (79.5\% vs. $72.2 \%)$ and those who had secondary education $(79.5 \%$ vs $40 \%)(p=0.0264)$. The participants who were civil servants were more knowledgeable about BSE compared with those who were traders, farmers or housewives $(61.9 \%$ vs $22.8 \%$; $\mathrm{p}=0.0003)$. There was no association between participants' knowledge of BSE and their reported religion. Significantly more participating women who reported insufficient income levels had no knowledge of BSE compared with those who had sufficient income $(78.9 \%$ vs $64.6 \% ; \mathrm{p}=0.008)$. 


\section{Practice of breast self-examination}

Table 3: $\quad$ Practice of breast self-examination $(\mathrm{N}=345)$

\begin{tabular}{|c|c|c|}
\hline & Practice items & $\begin{array}{l}\text { Yes } \\
(\%)\end{array}$ \\
\hline & How do you examine your breasts? & \\
\hline 1. & Stand in front of a mirror. & 12.8 \\
\hline 2. * & $\begin{array}{l}\text { Look at each breast and note any difference in the shape, the size, the } \\
\text { nipples or the skin darkness. }\end{array}$ & 33.9 \\
\hline 3. * & Check for swelling, increased warmth or tenderness in both breasts. & 20.6 \\
\hline 4. & $\begin{array}{l}\text { Look at the nipples for the size, the shape and the direction in which they } \\
\text { point. }\end{array}$ & 19.1 \\
\hline 5. * & Check for rashes or sores and nipple discharge. & 12.8 \\
\hline 6. & $\begin{array}{l}\text { Look at each breast while putting the hands over the head and press them } \\
\text { on the side. }\end{array}$ & 18 \\
\hline 7. * & Check whether the breasts are equal in front of a mirror. & 13.6 \\
\hline 8. & Lie down on a bed to check each breast. & 12.2 \\
\hline 9. * & Look at the left breast and note any difference from the right breast. & 13.9 \\
\hline 10. * & Place a pillow under the left shoulder and place the arm over the head. & 13 \\
\hline 11. * & Palpate the entire breast round. Note any swelling or tenderness. & 14.8 \\
\hline 12. * & Squeeze the nipple gently and note any discharge. & 20.3 \\
\hline 13. * & Do the same for the right breast, sitting up and with the arms at the sides. & 20.6 \\
\hline 14. * & $\begin{array}{l}\text { Do you sit up and raise your arm to palpate the tail of the breast and check } \\
\text { for swelling or tenderness? }\end{array}$ & 43.8 \\
\hline 15. & Do the same for the right side. & 29.6 \\
\hline
\end{tabular}

Table 3 shows that the practice of BSE was generally low: $66.1 \%$ of the participants were not able to perform the fifteen items on the BSE practice checklist properly, while less than $20.0 \%$ of the participants showed adequate practice in the step-by- step procedure in the 12 items on the BSE checklist. About a third (33.9\%) reported that they practise checking the breasts for any difference in shape, size and the nipples and skin darkness. 
Table 4: Socio-demographic characteristics and practice of breast selfexamination $(\mathrm{N}=345)$

\begin{tabular}{|c|c|c|c|c|c|}
\hline \multirow[b]{2}{*}{$\begin{array}{l}\text { Socio-demographic } \\
\text { characteristics }\end{array}$} & \multicolumn{4}{|c|}{ Practise breast self-examination } & \multirow[b]{2}{*}{ p-value } \\
\hline & \multicolumn{2}{|c|}{ Yes } & \multicolumn{2}{|l|}{ No } & \\
\hline Age (in years) & & & & & 0.2207 \\
\hline $20-30$ & 27 & 21.1 & 101 & 78.9 & \\
\hline $31-40$ & 16 & 14.0 & 98 & 86.0 & \\
\hline $41-50$ & 16 & 25.0 & 48 & 75.0 & \\
\hline$>50$ & 10 & 25.6 & 29 & 74.4 & \\
\hline Marital status & & & & & $0.0004^{*}$ \\
\hline Never married & 18 & 41.9 & 25 & 58.1 & \\
\hline Ever married & 5 & 16.9 & 251 & 83.1 & \\
\hline Education & & & & & $0.0051^{*}$ \\
\hline No education & 26 & 13.7 & 164 & 86.3 & \\
\hline Primary & 32 & 27.8 & 83 & 72.2 & \\
\hline Secondary & 11 & 27.5 & 29 & 72.5 & \\
\hline Occupation & & & & & $0.0001^{*}$ \\
\hline Trading/Housewife/Farming & 55 & 17.0 & 269 & 83.0 & \\
\hline Civil service & 14 & 66.7 & 7 & 33.3 & \\
\hline Religion & & & & & 0.1003 \\
\hline Christianity & 35 & 17.0 & 171 & 83.0 & \\
\hline Islam/Traditional & 34 & 24.5 & 105 & 75.5 & \\
\hline Income level & & & & & $0.0004^{*}$ \\
\hline Sufficient & 45 & 45.4 & 54 & 54.6 & \\
\hline Insufficient & 24 & 9.8 & 222 & 90.2 & \\
\hline
\end{tabular}

*Significant at $p>0.05$.

Table 4 shows that there was no difference in BSE practice across age groups $(\mathrm{p}=0.2207)$. Significantly more married, widowed and divorced participants reported no practice of BSE compared with single participants $(83.1 \%$ vs $58.1 \%)(\mathrm{p}=0.0004)$. Similarly, significantly more participants with no education reported no practice (compared with those who had primary education (86.3\% vs 72.2 $\%)$ or secondary education $(86.3 \%$ vs $72.5 \%)(\mathrm{p}=0.0051)$. The majority of participants who were traders, farmers or housewives reported no BSE practice compared with those who were civil servants $(83.0 \%$ vs $33.3 \%)$ ( $\mathrm{p}=0.0001)$. There was no difference in BSE practice across reported religions $(\mathrm{p}=0.1003)$. Significantly more participants who reported insufficient income level reported no practice $(90.2 \%)$ compared with those who had sufficient income level $(90.2 \%$ vs $54.6 \%)(\mathrm{p}=$ 0.0004). 


\section{Discussion}

The majority of the participants (74.8\%) were not aware of the knowledge of BSE, and $80 \%$ do not practise BSE among the rural dwellers. This was corroborated by Olowokere, Onibokun and Irinoye (2012), Ahuja and Chakkrabarti (2010) and Mugivhi, Maree and Wright (2011), who say that many women in the rural areas do not practise BSE. The age group of the participants in the study ranged between 20 and 50 years. About $74.8 \%$ of the participants had low knowledge of BSE, and $76.5 \%$ do not practise BSE. This result is corroborated by Afolayan (2008) and Ravichandran, Al-Hamdan and Mohamed (2011), who state that women of this same age group do not practise BSE. It is important to create an awareness programme on BSE for all the women in all age groups from menarche to menopause. Age is an important factor in the occurrence of breast cancer. This is supported by Sandhu et al. (2010) who state that the age of women at first menstruation (or menarche), during the birth of the first child, or at menopause, determines the incidence of breast cancer. The findings show the need to develop an empowerment programme for women in the rural areas.

The majority of the married participants (77.5\%) lack knowledge of BSE, and $83.1 \%$ do not practise BSE. This was contrary to the study by Ravichandran, Al- Hamdan and Mohamed (2011) who assert that women of 45 years, who are married, practise BSE than the single women. The married women are usually exposed to health information and healthcare facilities during the antenatal and postnatal care, infant welfare clinic and general well-being clinic. The married women have performed many roles in the family such as rearing the children, helping with family income to support their spouses, and also working as traders, farmers, housewives or civil servants. Developing an empowerment programme for the rural women by providing health information on the knowledge and the skills of BSE practice is necessary, as revealed by this study. This is supported by Bhengu (2010) and Parvani (2011) who state that dissemination of health information is necessary for acquiring BSE knowledge and practice in the rural women.

The participants with no formal education and those who had primary education were in the majority of those with low levels of BSE knowledge and practice. This is supported by studies by Khokher et al. (2012), Ravichandran et al. (2011), and Rasu, Rianon and Shahidullah (2011). These authors say that that higher education levels are associated with increased uptake of health information and behaviour changes such as BSE. Study findings revealed an urgent need to tailor health education to the needs of the women who have lower levels of education. The intervention development programme should include demonstration of BSE with the breast model, communicating the BSE messages using BSE pamphlets containing knowledge about BSE practice, which were precise, concise, in visible letters and had illustrations of the BSE step-by-step procedure inside, songs, and women health day. The BSE training should be concerned with choosing an appropriate and a convenient place, an appropriate time, and ability to meet in small groups using the local language for the rural women activities.

The religious beliefs of the participants indicate that they had low knowledge and practice of BSE. This is supported by Okobia, Bunker, Okonofua and Osime (2006) who claim that religious beliefs, fatalism affect the performance of breast cancer screening among women. Ravichandran et 
al. (2011) also state that many women in Nigeria associate breast cancer with spiritual affliction rather than religion.

The occupations of the participants revealed the low levels of BSE knowledge and practice among the participants who were traders, farmers or full-time housewives. In Nigeria, gender roles exist among families; women have no clear boundaries between doing their occupation and being mothers and wives. This may be responsible for the participants' low knowledge and practice of health behaviour such as BSE. This finding concurs with another study that states that occupations of the women affect BSE practice (Afolayan 2008). Occupation when considered with insufficient income level of the majority of the participants explains the level of poverty among the women and their uptake of health-seeking behaviour. This is consistent with another study on BSE knowledge and practice by Sim, Seah, and Tan (2009), which states that Malaysian women with low socioeconomic status and low level of education do not practice BSE due to lack of knowledge. This shows that participants who had sufficient income level and had education are more likely to practise BSE.

\section{Conclusions}

Many studies have been done to promote action and prevention of breast cancer through BSE practice (Olowokere et al. 2012; Awodele, Adeyomoye and Oregba 2009). The study revealed that the majority of the participants in this rural setting showed inadequate knowledge and practice of BSE. Considerable work needs to be carried out on developing an education programme appropriate to enhance BSE practice among the rural women. However, long-term follow-up should be conducted to confirm sustainability of the programme in the community, individuals and health workers. The study could guide the health workers for delivering preventive health information to any diverse population towards reduction of mortality associated with breast cancer.

\section{Recommendations}

The study demonstrates that the participants have low knowledge and practice of BSE. Based on the study findings, the participatory approach could be adapted to developing an educational programme for delivering preventive health information to rural women. Further research is recommended to examine long-term effectiveness in order to evaluate the sustainability of BSE practice among the rural women. A quasi-experiment approach could be conducted to provide stronger evidence for the effectiveness of the programme. Furthermore, replication of this study in other settings that include rural women or other population should be considered.

\section{Health workers}

Health information dissemination should be made available to women in the rural areas by health workers on breast cancer prevention through knowledge and practice of BSE, which corroborated the study by Olowokere et al. (2012). Health workers should promote strategies for reminders at every opportunity of the women gatherings such as in the religious centres, the market meetings, and during the women clinic days. BSE communicating messages such as BSE pamphlets, songs and demonstrations with models should be used for emphasis. The implementation activities should integrate motivational conversation and BSE skill training. 


\section{Policy makers}

The results of the study revealed that the majority of the participants had no education and do not practise BSE. Thus, there is a need to strengthen and foster intersectoral collaboration among the stakeholders. It is advised that the local government authorities, non-governmental organisations, and philanthropists in the society make formal education available to the girl child at least at the primary school level through sponsorship and scholarship. Providing the girl children with education will improve their health-care-seeking behaviour when they become adults. Also, the stakeholders need to make funds available for regular advertisements in the local media.

\section{Research}

Further research should be conducted on providing health information to women in the rural areas of other geographical zones in Nigeria and in other developing countries.

\section{Implications of the study}

The implications of the study findings revealed that the socio-demographic characteristics of the women had a bearing on the knowledge and practice of BSE. Imparting skills to BSE procedure will play major role in enabling attitudinal changes in the practice of BSE. This attitudinal change in the women will promote self-empowerment and sustenance of BSE knowledge and practice as it is indicated in the empowerment programme developed. Such practice, if maintained, will be passed down to generations. The empowerment programme developed could guide the public health nurses for delivering preventive health information to the women on the practice of BSE.

\section{Limitations of the study}

The study was cross-sectional conducted in one of the six geo-political zones of the country. The limitations of this study are related, following the BSE practice of the attendances for just three months. Therefore, the sustainability of their practice could not be evaluated for the long-term followup. The BSE is performed on a monthly basis so the long-term benefits of the empowerment programme developed among the women are recommended.

\section{Acknowledgements}

The researcher appreciates those who granted her permission to conduct the study: the local government health authority, the University of the Western Cape, and the Higher Degrees and Senate Research Committee. The women who participated in the study, the health workers of the Iddo local government, and the reviewer of this research work, are also appreciated. 


\section{References}

Ahuja, S. and N. Chakrabati. 2010. "Determine the Level of Knowledge of Breast Cancer Screening among Women in Tertiary Care in Mumbai, India." The Internet Journal of Public Health 1(1). http://ispub.com/IJPH/1/1/10062 (accessed 4 May 2014).

Akinde, O. R., A. A. Phillips, O. A. Oguntunde, and O. M. Afolayan. 2015. "Cancer Mortality Pattern in Lagos University Teaching Hospital, Lagos, Nigeria." Journal of Cancer Epidemiology Article ID 842032. http://dx.doi.org/10.1155/2015/842032

Akpo, E., M. Akpo, and A. Akhator. 2009. "Breast Cancer Knowledge and Screening Practices among Nigerian Medical Students." The Internet Journal of Health 11(2). http://ispub.com/ IJH/11/2/5445 (accessed 4 May 2014).

American Cancer Society. 2011. “Cancer Facts and Figures 2010.” Retrieved from www.cancer. org/acs/groups (accessed 23 February 2011).

Awodele, O., A. A. Adeyomoye, and I. A. Oreagba. 2009. "Knowledge, Attitude and Practice of Breast Cancer Screening among Nurses in Lagos University Teaching Hospital, Lagos Nigeria." Nigerian Quarterly Journal of Hospital Medicine 19:114-118.

Azubuike, S. O., and S. O. Okwuokei. 2013. "Knowledge, Attitude and Practices of Women towards Breast Cancer in Benin City, Nigeria." Annals of Medical and Health Sciences Research 3 (2): 155-160.

Bhengu, B. R. 2010. "An Investigation into the Level of Empowerment of Rural Women in the Zululand district of KwaZulu-Natal Province of South Africa." Curationis 33 (2): 4-12.

Brink, H., W. C. van Der Walt, and G. van Rensburg. Fundamentals of Research Methodology for Healthcare Professionals. 2nd ed. Atlanta: American Cancer Society, 2011.

Champion, K., and V. J. Strecher. 2002. "The Health Belief Model." In Health Behavior and Health Education: Theory, Research, and Practice, edited by K. Glanz, B. K. Rimer, and F. M. Lewis, 45-66, San Francisco: Jossey-Bass.

Ferlay, J., I. Soerjomataram, M. Ervik, R. Dikshit, S. Eser, C. Mathers, M. Rebelo, D. M. Parkin, D. Forman, F. Bray, and F. Globocan. 2012. Cancer Incidence and Mortality Worldwide: IARC CancerBase No. 11. Lyon, France: International Agency for Research on Cancer. http://globocan.iarc.fr (accessed 16 January 2015).

Forbes, L. J., L. Linsell, L. Atkins, C. Burgess, L. Tucker, L. Omar, and A. J. Ramirez. 2011. "Promoting Early Presentation Intervention Increases Breast Cancer Awareness in Older Women after 2 Years: A Randomised Controlled Trial.” British Journal of Cancer 105 (1): 18-21.

Khokher, S., M. U. Qureshi, N. A. Chaudhry. 2012. "Comparison of WHO and RECIST Criteria for Evaluation of Clinical Response to Chemotherapy in Patients with Advanced Breast Cancer." Asian Pacific Journal of Cancer Prevention 13 (7): 3213-18.

Mugivhi, N. H., J. E. Maree, and S. Wright. 2011. "Rural Women's Knowledge of Prevention and Care related to Breast Cancer." Curationis 32 (2) : 38-45.

Ogunbiyi, J. O., A. O. Fabowale, and A. A. Ladipo. 2010. Cancer incidence and top ten cancers in eleven local government areas in Ibadan, Nigeria and its environs, 2004-2008. Ibadan: M. Alofe Enterprise. 
Olowokere, A., A. Onibokun, and O. Irinoye. 2012. "Women's Health Beliefs and Breast Cancer Screening Practices in Nigeria." Africa Journal of Midwifery and Women's Health 6 (2): 91-97.

Parvani, Z. 2011. "Breast Self-examination, Breast Awareness and Practices of Systematic Review." Professional Medical Journal 18 (2): 336-339.

Rasu, R. S., N. J. Rianon, and S. M. Shahidullah. 2011. "Effect of Educational Level on Knowledge and Use of Breast Cancer Screening Practices in Bangladeshi Women." Health Care Women International 32:177-189.

Ravichandran, K., N. Al-Hamdan, and G. Mohamed. 2011. "Knowledge, Attitude, and Behaviour among Saudis toward Cancer Preventive Practice." Journal of Family and Community Medicine 18 (3): 135-142.

Sandhu, D. S., S. Sandhu, R. K. Karwasra, and S. Marwah. 2010. "Profile of Breast Cancer Patients at a Tertiary Care Hospital in North India." Indian Journal of Cancer 47:16-22.

Sim, H. L., M. Seah, and S. M. Tan. 2009. "Breast Cancer Knowledge and Screening Practices: A Survey of 1,000 Asian Women.” Singapore Medical Journal 50:132-138.

Welman, C., F. Kruger, and B. Mitchell. 2005. Research methodology. South Africa: Oxford University Press.

World Health Organization. 2008. The global burden of disease: 2008 update. Geneva: WHO. 